\title{
The development of a model for teaching information literacy to nursing students through cross-professional collaboration
}

\author{
Anita Nordsteien*, May-Elin Thengs Horntvedt, Nina Therese Holmen \\ Vestfold University College \\ *Contact: \\ E-mail: anita.nordsteien@hive.no
}

\section{Abstract}

This paper describes experiences from a collaborative project between the nursing educators at the Institute of Nursing Science and the health sciences librarians at Vestfold University College in Norway. The aim of the project was to develop a teaching model to improve the nursing students' information searching and critical appraisal skills. 


\section{Introduction}

Information literacy (IL) in healthcare involves searching for and using the best available knowledge that leads to health improvement. It is essential that health care professionals use the most up-to-date information and do not rely on knowledge that may, in the worst case scenario, be outdated and even harmful to patients (Bjørndal, Flottorp, \& Klovning, 2013). These skills are essential for self-directed continuous learning. To ensure good practice in their subsequent professional lives, the students need to learn how to find, evaluate and use information for further learning.

Evidence-based practice (EBP) means conscious use and application of various sources of knowledge in practice. EBP health services involve professional decisions that are founded on scientific knowledge, experiential knowledge and patients' preferences in a given situation (Nortvedt, Jamtvedt, Graverholt, Nordheim, \& Reinar, 2012).

\section{Interdisciplinary development process}

The development work for the project in focus started in the academic year 2011/2012. This initially involved examining the curriculum of the nurse training programme and specifically focusing on the lesson plans related to IL. A number of studies have revealed that nurses and nursing students are not very adept at IL (Duncan \& Holtslander, 2012; Ivanitskaya, Klem \& Weiss, 2005; Mittermeyer, 2005; O'Boyle, \& Casey, 2006; Ragneskog \& Gerdner, 2006). It is pointed out that nurses will have challenges working with EBP, because of their inability to locate and critically evaluate information (Barnard, Nash, \& O'Brien, 2005; Duncan \& Holtslander, 2012; Klem \& Weiss, 2005). These studies argue that major changes in the teaching of IL are required, particularly in the form of a closer collaboration between nursing educators and librarians. It is recommended that the teaching of IL should be systematically integrated into the programme and closely related to the course requirements and assignments.

Klem and Weiss (2005) claim that if classes about IL are taught from both the educators and librarians perspectives, the subject matter is regarded as even more meaningful by students. This leads to them being more motivated to acquire these skills and apply them in their work. The study of Klem and Weiss also includes an overview of key resources and tools for EBP, which has been central to our work in developing a new teaching model.

The findings of these studies combined with our curriculum examination resulted in us focusing on the objective of improving IL teaching in our nurse training programme.

We also examined what is emphasised when teaching IL in other Norwegian nurse training programmes. A questionnaire developed in Google docs was circulated by e-mail to 32 libraries with nurse training programmes in Norway. The questionnaire recipients were all librarians and the response rate was $68,8 \%$. The librarians were mainly asked about the frequency, content and cross-professional collaboration in IL teaching. The responses were summarised using the analysis tool in Google Docs.

\section{Results}

The survey revealed great variations between the respondents regarding the IL teaching in the nurse training programme. The results that we found most significant in relation to our focus are presented below. 


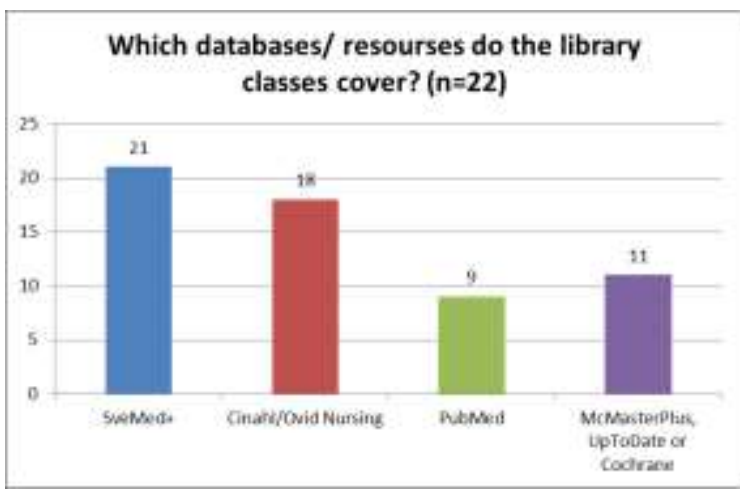

Figure 1

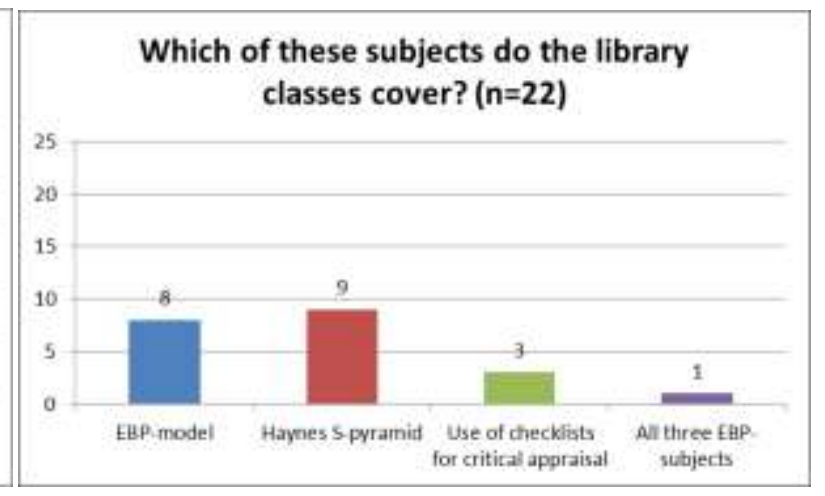

Figure 2

Figure 1 illustrates that only half of the respondents were using sources that are central to EBP (Cochrane, UpToDate, McMaster Plus), while 21 out of the 22 respondents were using SveMed + where most articles are published in the Scandinavian languages, but are not research articles. Figure 2 illustrates that only one respondent teach all the EBP-subjects (EBP-model, Haynes Spyramid, checklists).

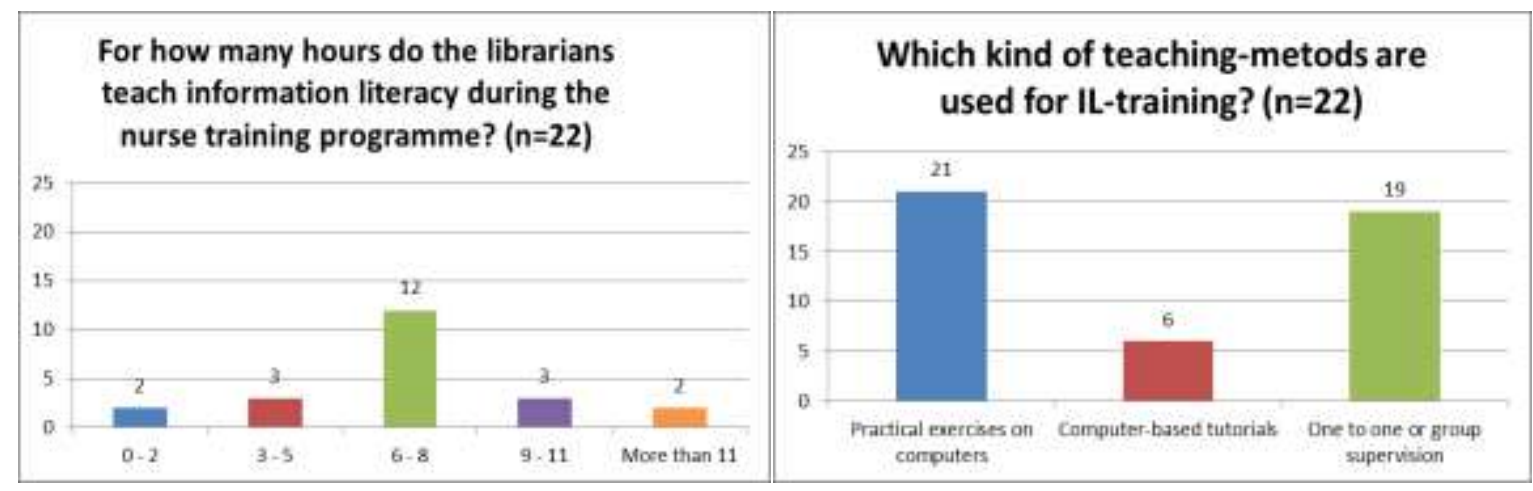

Figure 3

Figure 4

Figure 3 illustrates that 12 of the respondents teach IL 6-8 hours in their programme, 5 teach more and 5 teach less than that. Figure 4 illustrates that 19 of the respondents said that they are giving one to one or group supervision. 21 of the respondents were conducting parts of the library teaching in the classroom with practical exercises on computers, but only 6 claimed that they offer computer-based tutorials.

\section{Implementation of a teaching model for IL}

Based on our preliminary work we developed a teaching model illustrated in Table 1 below. Librarians and nursing educators should collaborate on teaching methods in the literature search for research-based knowledge. We have emphasised different teaching methods, such as classroom teaching, group seminars, demonstrations and practical exercises in computer rooms.

\begin{tabular}{|c|l|l|l|}
\hline Time & \multicolumn{1}{|c|}{ Duration } & \multicolumn{1}{c|}{ Content } & Participants \\
\hline 1st year & $\begin{array}{l}\mathbf{1} \text { hour in the } \\
\text { library }\end{array}$ & $\begin{array}{l}\text { Introduction to library services, presenting the teaching } \\
\text { model, the library website, databases (emphasis on the } \\
\text { Norwegian library catalogue and the Norwegian Electronic } \\
\text { Health Library, NEHL), reference management }\end{array}$ & Librarians \\
\hline
\end{tabular}




\begin{tabular}{|c|c|c|c|}
\hline 1st year & $\begin{array}{l}2 \text { hours in } \\
\text { computer room }\end{array}$ & $\begin{array}{l}\text { NEHL, Haynes S-pyramid, PICO, basic search techniques, } \\
\text { intro to critical appraisal, assessment of the result lists. } \\
\text { Research vs. academic article, intro checklists. Guidance in } \\
\text { relation to literature search for a study assignment in } \\
\text { PubMed }\end{array}$ & $\begin{array}{l}\text { Librarians and } \\
\text { nursing } \\
\text { educators }\end{array}$ \\
\hline 2nd year & $\begin{array}{l}2 \text { hours in } \\
\text { computer room }\end{array}$ & $\begin{array}{l}\text { EBP perspective, Haynes S-pyramid, critical appraisal, } \\
\text { checklists. Guidance in relation to literature search for a } \\
\text { study assignment in Cinahl and McMaster Plus }\end{array}$ & $\begin{array}{l}\text { Librarians and } \\
\text { nursing } \\
\text { educators }\end{array}$ \\
\hline 2nd year & $\begin{array}{l}2 \text { hours in } \\
\text { computer room }\end{array}$ & $\begin{array}{l}\text { Repetition search technique, PICO and PubMed. Guidance } \\
\text { in relation to literature search for a study assignment }\end{array}$ & Librarians \\
\hline 3rd year & $\begin{array}{l}2 \text { hours in } \\
\text { computer room }\end{array}$ & $\begin{array}{l}\text { The Norwegian Electronic Health Library with an emphasis } \\
\text { on knowledge hierarchy, guidelines. } \\
\text { Guidance in relation to literature search for a study } \\
\text { assignment in PubMed and McMaster Plus }\end{array}$ & $\begin{array}{l}\text { Librarians and } \\
\text { nursing } \\
\text { educators }\end{array}$ \\
\hline 3rd year & $\begin{array}{l}\text { 2-hour } \\
\text { workshop in } \\
\text { computer room }\end{array}$ & $\begin{array}{l}\text { Repetition of PubMed, Cinahl, McMaster Plus, Cochrane. } \\
\text { Guidance in relation to thesis: PICO, critical appraisal }\end{array}$ & Librarians \\
\hline
\end{tabular}

The teaching content is grounded in the structure of the EBP-model, which is based on the following six steps: reflection, question formulation, literature search, critical appraisal, application and evaluation (Nortvedt, et al., 2012). The librarians and the nursing educators collaborate primarily on the first four steps; the last steps are the nursing educators' responsibility.

In our model, the teaching of IL is linked directly to study assignments that have relevant clinical application. The nursing educators' job is to support students and librarians with nursing knowledge and to promote reflection to identify relevant keywords. The teaching programme developed recommends that over the three years of study, both librarians and nursing educators use a framework called Patient / Problem, Intervention, Comparison and Outcome (PICO) in order to facilitate and simplify the process of finding relevant keywords. Using this framework the topic or question related to clinical issues is divided into relevant concepts (Nortvedt, et al., 2012).

Early in their first year of study, nursing students are introduced to the Norwegian Electronic Health Library (NEHL), which is a public electronic knowledge service. This library provides free access to research-based information such as guidelines, systematic reviews and scientific journals (Nylenna, Eiring, Strand, \& Rottingen, 2010). We use NEHL as a portal when teaching how to search for literature. We want to ensure that future nurses become familiar with the same portal that they will have access to anywhere in the health-care services.

Our teaching in literature search is grounded in the EBP-model throughout the study programme. Using guidelines, systematic reviews etc. as decision support in practice are an important principle in EBP. Canadian researchers (Dicenso, Bayley, \& Haynes, 2009) have developed a pyramidal system for organising knowledge sources into six levels to guide clinical decision-making. The purpose of this system is to facilitate easy access to high quality research. 
On the highest layer of this model is the future system layer; the next level includes summaries, then synopses of syntheses, followed by syntheses and finally synopses of studies and original studies. The search engine McMaster Plus is available through NEHL.

At times students find that there are no guidelines or summarised research studies on their topics of focus, therefore it is important that they also master searching for original studies. In the first year of study they are introduced to the PubMed-database that has a simple and logical user interface. Cinahl is also an important database for nursing, but it can be more complicated to search in, therefore it is only introduced in the second year. In the third year, we emphasise conducting searches in Cochrane and UpToDate via McMaster Plus. We also offer a ten-week course focusing on EBP, management and supervision in nursing. In this course, students' skills in using the EBP-model are reinforced and they are made aware of the various sources of knowledge that can be used to support their future professional work.

Exercises in critical appraisal of scientific papers are included throughout the whole programme. In the first year of the course, students are introduced to checklists developed by the National Knowledge Centre. The checklists are aids to use when appraising papers. We ensure that students have a grounded knowledge of scientific theory and research methods throughout the nurse training programme with an increased focus on this in the third year. In the final year, an important part of the collaboration between nurse educators and librarians is the participation of a librarian with the nursing educators in an article seminar. In this seminar the students present their literature-search process and critical assessment of selected articles to fellow students, the participating librarian and nursing educators. Feedback on their work is then given by all the participants.

\section{Experiences}

As the focus on EBP in health care gradually increases, we have experienced that our emphasis on this area is right. By defining interdisciplinary collaboration we believe that our model will contribute to strengthening the students' competence in IL. This collaboration involves representatives from both professions planning the course content together, attending the same classes or workshops, and sometimes, alternating teaching to focus on different aspects of IL.

As mentioned earlier, it is expected that health professionals make decisions based on evidence (EBP), thus, we think that an increased focus on IL is necessary. We believe that the presented model may contribute to strengthening the students' competence in IL, so that future nurses attain the skills that are required by continuous quality improvement of health services. We think the model ensures that nursing students, who graduate have the necessary competence in managing knowledge that may be obtained via databases.

Our experiences from this project show that interdisciplinary collaboration on IL is an important focus in nursing education. Evaluation of this collaborative work shows that the competences of both professions has significantly improved and in the process helped to clarify the respective roles of the librarian and nurse educator. Above all, we think that this collaboration has been important both for the students' learning process and the professional development of the librarians and nursing educators. We are now planning a study where the aim is to evaluate our teaching model by examining the students' final theses.

\section{References}

Barnard, A., Nash, R., \& O'Brien, M. (2005). Information literacy: Developing lifelong skills through nursing education. Journal of Nursing Education, 44(11), 505-510.

Bjørndal, A., Flottorp, S., \& Klovning, A. (2013). Kunnskapshåndtering i medisin og helsefag [Knowledge management in medicine and health sciences] (3 $3^{\text {rd }}$ ed.). Oslo: Gyldendal akademisk. 
Dicenso, A., Bayley, L., \& Haynes, R. B. (2009). Accessing pre-appraised evidence: Fine tuning the 5S model into a 6S model. Evidence-Based Nursing, 12(4), 99-101. doi:10.1136/ebn.12.4.99-b

Duncan, V., \& Holtslander, L. (2012). Utilizing grounded theory to explore the information seeking behavior of senior nursing students. Journal of the Medical Library Association : JMLA, 100(1), 20-27. doi:10.3163/1536-5050.100.1.005

Ivanitskaya, L., O'Boyle, I., \& Casey, A. M. (2006). Health information literacy and competencies of information age students: Results from the interactive online Research Readiness SelfAssessment (RRSA). Journal of Medical Internet Research, 8(2). doi:10.2196/jmir.8.2.e6

Klem, M. L., \& Weiss, P. M. (2005). Evidence-based resources and the role of librarians in developing evidence-based practice curricula. Journal of Professional Nursing 21(6), 380387. doi:10.1016/j.profnurs.2005.10.004

Mittermeyer, D. (2005). Incoming first year undergraduate students: How information literate are they? Education for Information, 23(4), 203-232.

Nortvedt, M. W., Jamtvedt, G., Graverholt, B., Nordheim, L. V., \& Reinar, L. M. (2012). Jobb kunnskapsbasert!: En arbeidsbok [Work in an evidence-based way!: A workbook] (2nd ed.). Oslo: Akribe.

Nylenna, M., Eiring, O., Strand, G., \& Rottingen, J. A. (2010). Wiring a nation: Putting knowledge into action. Lancet, 375(9719), 1048-1051. doi:10.1016/s0140-6736(09)61832-8

Ragneskog, H., \& Gerdner, L. (2006). Competence in nursing informatics among nursing students and staff at a nursing institute in Sweden. Health information and libraries journal,23(2), 126-132. doi:10.1111/j.1471-1842.2006.00643.x 